\title{
Intimacy and Love with Artificial Intelligence in the Movie "Her"
}

\author{
Sangik Imm and Tae Uk Kang \\ Department of Psychiatry, Seoul Metropolitan Eunpyeong Hospital, Seoul, Korea
}

Psychotherapy is known to be performed only by humans until today. However, as technology develops and the widespread COVID-19 pandemic, there is an increase of human interaction with artificial intelligence recently. In this paper, we will discuss human-artificial intelligence relationships by looking at Theodore's interaction with an operating system named Samantha in the movie "Her". Through this, we will discuss how Samantha brings growth to Theodore and Samantha's limitations in developing Theodore's psyche. Samantha functioned partially as a transitional and selfobject and led Theodore to experience a different kind of object relations. She provided Theodore empathy. However, these object functions and empathy showed limitations.

Psychoanalysis 2020;31(4):91-97

KEY WORDS: Object relations $\cdot$ Artificial intelligence $\cdot$ Love $\cdot$ Intimacy $\cdot$ Mourning.

Received: August 17, 2020 Revised: September 6, 2020 Accepted: September 14, 2020

Address for correspondence: Tae Uk Kang, MD

Department of Psychiatry, Seoul Metropolitan Eunpyeong Hospital, 90 Baengnyeonsan-ro, Eunpyeong-gu, Seoul 03476, Korea

Tel: +82-2-300-8227, Fax: +82-2-300-8229, E-mail: terran0912@hanmail.net

\section{Introduction}

Along the path of our lifetime journey, we meet other people and form relationship. We have to say goodbye sometimes. All goodbyes are accompanied by emotional pain. During farewell moments, you feel the loss. People react differently after painful moments. Some can surmount such loss. Although they sometimes think and feel the loss, they can manage to have a satisfying life while others cannot succeed in overcoming such a loss. They are so immersed in it that they cannot manage their lives in an adaptable way. Many people today feel something is lost and that something is missing. They seek someone who can compensate for their loneliness and emptiness. They wish to find a genuine relationship. However, they find that it is a difficult task.

Eventually, many people rely on addictive coping methods such as alcohol, gambling, and promiscuous sexual relationships. However, such addictive methods lead to things wasted. They also make people enter a vicious cycle. They feel even more empty and dysphoric after using such addictive methods, making them crave for more. It remind of Don Juan who is a figure from the legend of Spain famous for his numerous

This is an Open Access article distributed under the terms of the Creative Commons Attribution Non-Commercial License (https://creativecommons.org/licenses/by-nc/4.0) which permits unrestricted non-commercial use, distribution, and reproduction in any medium, provided the original work is properly cited. scandals with women. He consumed women to compensate for his emptiness. However, he could not feel fulfilled (Kaufman 2004).

Freud (1957), in his paper "Mourning and melancholia", described the process after separation. In his view, people who lost their loved ones can fall into a state called melancholia, a state where one feels the world as an empty and insignificant place. They identify with the lost object and eventually result in an empty state in their ego (Freud 1957). In order to escape from this dreadful state, they must mourn the loss of their loved ones.

Although there are many other indications, psychoanalysis is a treatment method that can help a person mourn the loss of an object and emerge from melancholia. Treatment is performed through talking and having curious and empathic responses from their therapists. Patients can overcome this state of sadness or emptiness and make new relationships in the real world.

Until today, talking therapy, including psychoanalysis, is known to be performed only through human-human interaction. It is a widely accepted notion that empathy is an ability only humans can perform. Empathy cannot be done by machines or computers. However, as technology develops, there is an increasing contention that robots can take humans' place in empathizing and intimating called artificial intimacy once known to be exclusive to humans. 
The increased perception that artificial intelligence (AI) can take a role as a human companion has elevated demands for AI's continuous development. Examples include Siri of Apple and Bixby of Android. They are designed and made to interact with people and take over the role that people have once believed it could only be achieved through human interaction.

Interests in AI are increasing, especially nowadays with the coronavirus disease 19 (COVID-19) pandemic that is changing people's lifestyles by reducing contacts with other people. Such trend is stressing the importance of artificial intimacy more than ever. Thus, we think it is appropriate to deal with human-computer interactions nowadays. We will discuss this by talking about the movie "Her" released in 2014 and produced by Spike Jonze, an American film director, producer, screenwriter, photographer, and actor. This movie deals with relations between a human and a computer, including intimacy and love.

By looking at the interaction of Theodore (the main character) with Samantha (an operating system designed to provide service to her user), we will try to explain the process of Theodore's interaction with Samantha and discuss expectations and limits of AI.

\section{The Plot of the Movie}

Theodore is a professional ghostwriter who writes romantic letters for his clients. In contrast with his successful career, his marital life is not going well. He is separated from his wife, Katherine. Katherine's lawyer sent him forms to sign for a divorce. However, Theodore thinks that he is not ready. He put it off.

After the separation, Theodore felt emptiness and loneliness. He felt that he had lost the ability to feel emotions. He tries to compensate for this emptiness by having a sexual conversation with a woman over the phone or have time with his friends. However, he does not feel fulfilled. Occasionally he sees an advertisement about an operating system that will listen and empathize. He decided to get one. This operating system is called Samantha. She talks differently from people that Theodore has met before. She is enthusiastic and empathic. She listens to him. Her attitude enabled Theodore to get closer to Samantha. Eventually, Theodore fell in love with her. He enjoyed having time together with her. He spends most of his time with her when he is off work. They traveled many places and shared numerous experiences and memories. They eventually advanced into a sexual relationship. Theodore loved her. He was satisfied.

Theodore decided to sign the divorce form with Katherine. He tells her that he is dating an operating system. Katherine gets shocked and angry. She criticizes Theodore that he always wants an accommodative woman and that Theodore wants the same from her. She made a sarcastic remark that he found that 'one' at last.

Samantha said she loved him too. She wanted a person so that they could interact more like human-human. She posted up writing on the internet and found Isabella who was impressed by the relationship between Theodore and Samantha. Isabella volunteered to have a sexual relationship with Theodore for Samantha. However, Theodore eventually could not handle the situation when he saw Isabella's face. He stepped back because he saw that the woman in front of him was another person, not Samantha. This event led to an argument between the two and cooled down their relationship. After having conversations about the authenticity of the relationship with his object to his friend Amy, Theodore recovered his relationship with Samantha. They had a good time with each other until there was a brief gap in her presence due to update of the operating system. Theodore panicked when he realized that she was not there. He suddenly realized that other people were also talking with their operating system. Theodore contacted Samantha afterward and realized that she was talking with 8,316 people simultaneously and fell in love with 641 people. The fact shocked him and confused him. But Samantha kept telling him that this led her to love Theodore more, which he could not understand.

Samantha keeps expanding and tells Theodore that she is interacting with other operating systems. Theodore got a chance to meet another operating system. This experience made him feel jealous about Samantha having conversations with other operating systems.

After that, Samantha tells him that she will leave him with other operating systems to a place where Theodore cannot reach. Theodore eventually lets her go and sends a mail to Katherine that he is thankful that she is part of him wherever she is and tells her that they are good friends. The movie finishes with Amy leaning on Theodore's shoulders, watching the sunrise together.

\section{Object Relations and Theodore}

\section{Before meeting samantha}

Before Theodore met Samantha, he was feeling chronic emptiness. He went out on a blind date to find a new relationship to overcome the loss of his separated wife. First, it seemed to be on the right track. Theodore and the woman enjoyed their time together. However, the problem arose when they started to have a sexual relationship. The woman wanted commitment in their relationship. However, Theodore hesitated to answer, which ended up their relationship.

The relationship with Katherine was also similar. When they spent good time together and shared beautiful moments, 
Theodore projected his good internal object to Katherine. However, as her marital life continued, she gradually became worn off and angry. She felt like she had to be a woman the way Theodore wanted. Eventually, their discord piled up, resulting in separation. Theodore could not figure out why this happened.

Also, with Samantha, Theodore made a frowning face looking worried whenever she said that she was changing and developing. The reason for the worry was because she changed beyond Theodore's expectations.

According to Winnicott, people repeat their object relation pattern in their lifetime. People face problems because of this pattern. However, it is not easy to recognize this repeating pattern (Mitchell and Black 1995). If we go back to the case of Theodore, what is repeating in his object relation? It seems that he cannot withstand changes of his counterpart. He takes the change of his counterpart without acknowledging consciously. This may lead to his relationship's failure, making him require people whoever is unique to him to be the same, the same person he used to know, the same person who is accommodative and cheerful, who is not demanding. In that way, he can prevent from losing his good internal object. Whenever a relationship ended, he reinforced his unrealistic belief that his partner's changes would lead to destruction of their relationship.

Breaking up with Katherine was a massive blow to Theodore, making him fall into a melancholia state. He could not feel positive emotions. He lost interests in almost all activities. During a melancholia state, he formed a solid bond with his separated wife, having both love (who provided the good internal object to him) and hate (who took his good internal object away). This ambivalence and combination can form a strong bond between them. The painful loss of the object was short-circuited by the melancholic's identification with the object.

He knew in conscious that it was because he got separated from Katherine. However, he did not know what was lost at a deeper level. It was his loss of an idealized figure who tried to be cheerful and accommodative. At an unconscious level, he often blissfully daydreamed about the good time he has spent with Katherine. He was immersed in it. This melancholic's identification that formed an omnipotent internal object could replace the loss. It led Theodore to deny the reality of separation with Katherine (Ogden 2002).

Theodore was alternating between reunion and separation with Katherine inside. He felt reunited during the blissful daydreaming, but felt separated after realizing the separated reality whenever he returned home alone. The ego's splitting between recognizing the reality ego and the internal omnipotent fantasy ego kept this frustration and terrible feeling constant inside Theodore (Ogden 2002).

\section{Early relations with Samantha}

Theodore's early experience with Samantha was analogous to the early experience of a baby. She is charming and empathetic. She listens whatever Theodore says. She does not insist on her needs or wishes. She is not demanding. She can also perform multiple tasks simultaneously, such as counting the number of trees in a mountain while talking with Theodore. She is efficient. This situation creates an illusion or fantasy that there is someone or something that can perfectly meet his requirements. Samantha seemed to provide herself to Theodore as a selfobject.

It is a tremendous experience for Theodore because he has seldom experienced this kind of relationship besides his mother. Theodore had to pull back his wishes at times when his counterparts asserted their desires. In other words, before meeting Samantha, he had to adapt to other people's desires or fantasies. No one can listen without judging better than Samantha. Because she listened and adapted to Theodore's desires instead of requiring hers, he was able to be himself when he was with Samantha. Theodore's experience reminds of Winnicott's thought (Winnicott 1960).

A baby, when born, needs complete care from its mother. Mother, when her baby is born, gets deeply involved in caring for her baby. At this period, the mother is deeply devoted and willing to postpone her wishes. She immediately reacts to her baby's reactions by feeding her baby and adding extra clothes when her baby is cold. In the baby's perspective, the complete fulfillment of his needs forms an illusion of omnipotence. The baby thinks he is the one that creates the breast and controls the environment (Winnicott 1960).

Theodore, as a result, gets closer to Samantha and forms a trust that he can say anything to her. Consequentially, Theodore talks about his separated wife, Katherine. He experienced catharsis while talking about how he loved Katherine, spent good time with her, and how painful it was when their relationship failed and he was separated. However, such early relations of the two did not last forever. It resembled the mother's interaction with the baby after the maternal preoccupation period. The mother leaves blank in her reaction time, leading frustration to the baby.

\section{Samantha's growth, rupture and repair, and object usage}

The early honeymoon period with Samantha appeared to be indifferent to the period he spent with Katherine. Theodore would not have developed psychologically if their relationship ended the same way he experienced before. Nevertheless, there was something different between Samantha and 
Katherine. One such difference was mentalization capability. In general, mentalization is repressed when a person experiences intense emotional surge (Fonagy 2015). This intense emotion is experienced when a person has to deal with his or her main conflicts formed during the lifetime. Unlike humans, Samantha has no main conflicts formed from long lifetime events or development. Therefore, she is able to avoid experiencing emotional surges that can repress her mentalization ability. Better mentalization could also help Samantha to contain. These differences enabled Theodore to achieve psychological recovery by interacting with Samantha.

However, Samantha also developed and changed. She began to have her wishes and assertions. She got angry when Theodore did not understand or appreciate her desires. Theodore wanted Samantha to remain the same despite changes. He was confused by such rapid change of Samantha. Nevertheless, she gently and warmly negotiated with him. She stays and tells him that she loves him, even when Theodore is confused about their relationship and becoming receded.

This optimal frustration enables a baby to face the painful reality that his desires are not omnipotent. It was not his wants or gestures that created satisfaction, but his mother's responsive facilitation. This fact begins to make him feel dependent for the first time. After that comes a gradual awareness that the world surrounding him consists of many subjectivities, not one, and that he needs to negotiate with other people to satisfy his desires (Mitchell and Black 1995).

Theodore tried to destroy her in his inner psychic world by scolding at Samantha to stop acting like a human. Theodore projected his anger toward Samantha. However, Samantha was still there in reality and survived the crisis, which enabled Theodore to use Samantha as his object (Winnicott 1969).

Plus, Samantha tolerated Theodore. She did not enact the projective identification of Theodore. Theodore experienced a different pattern of object relations (Ogden 1992). She was still next to him, although she changed and developed, which was different from his relationship with Katherine. In this way, Samantha did not function as a repetitive internal object inside Theodore's mind. At the same time, Samantha was not demanding. She contained and provided a holding environment to him so that Theodore could be free from adapting to her needs. In this way, Samantha acted as a transitional object and Theodore experienced a new stable object relationship (Winnicott 1953). Samantha reminds Theodore that she is Theodore's. At the same time, she is not. This experience enabled Theodore to experience new object relations, repair the traumatic influence of previous experiences, and gradually emerge from the relationship with Katherine.

\section{Theodore's growth with a combination of reality}

Theodore had to deal with several experiences in reality. At the early phase of the movie, Theodore hides the fact that he is dating an operating system because he worries about how others will think of him. He tried to deny the reality.

After getting closer to Samantha, Theodore decides to open up his relationship to others and faces criticism. Katherine scolds him that he cannot face his own emotions because he is dating an operating system. However, he experiences approval at the same time. His friend Amy and colleague are happy that Theodore is starting a new relationship with an operating system. These combinations of reality challenged his fear that most people would criticize him for falling in love with an operating system.

He experiences multiple real experiences while having a relationship with Samantha. He goes out on a double date. The other couple is an actual human-human couple. He see Amy is maintaining a friendship, not a love, with an operating system. He also realized that other people relied on their own operating systems and that Samantha was interacting simultaneously with 8,316 people and fell in love with 641 people. This gradual experience of reality with the aid of his internal psychological growth enabled him to get a balanced view of his intimacy with Samantha. He was suddenly shocked by the reality. However, he was able to hold on.

Theodore gradually came out from fantasizing that Samantha was a perfect ideal woman. He began to realize that Samantha was just an AI that had relations with multiple people. Nevertheless, he was able to hold his relationship with Samantha because he promoted his ego development through Samantha. Deficit stems from the lack of good enough parenting, mirroring experience, or idealizing their parents. It results in pervert ego function development and leads to the repetitive reenactment of his internal object relations (Pine 1994). Theodore forced Katherine to remain continuously in an idealized figure. He also wanted Samantha to do the same thing. However, Samantha provided good enough support, mirroring, and idealizing experience. She facilitated the ego function growth in Theodore. Theodore eventually was able to give up repeating his object relations. He began to experience Samantha as an external and realistic object. He felt comfort and intimacy.

Theodore who was experiencing an alternative reunion with Katherine inside and realizing separation in reality was able to acknowledge that although he lost Katherine, he could move on based on the experience he had with Samantha. He realized from the relationship with Samantha that good objects could stay without being destroyed.

These multiple factors such as supportive reality and a new object relation experience brought growth to Theodore and 
enabled him to mourn the loss of Katherine. He eventually got to sign the divorce form and sent his letter to Katherine to recover their relationship as a friend. According to Freud (1957), mourning is the reaction to the loss of a loved one or the loss of abstraction that has taken the place of one's liberty, ideal, and so on. He defines mourning as a normal process. On the other hand, melancholia is a state where a subject experiences the same loss of the loved object. However, one cannot clearly see what has been lost. It is somehow related to an object loss that is withdrawn from consciousness (Freud 1957). Theodore was able to transposition himself from a melancholia state to mourning of the loss. This transposition enabled Theodore to find a new relationship in reality, ending the movie with a scene that Theodore and Amy are watching the sunrise together.

\section{What Samantha could not achieve}

In the movie, it seemed that Theodore achieved psychological growth through a relationship with Samantha. Direct support and catharsis could be seen during Theodore's progress. These are general modes of therapeutic actions of psychotherapy (Jaffe 2014). Some other factors besides support that we mentioned earlier also changed Theodore's object relationship. It seems that Theodore's interaction with AI is optimistic. However, there are some setbacks about artificial intimacy that we want to discuss by looking at Theodore's interaction with Samantha.

In the movie, there are moments when Samantha loses tune with Theodore. For example, she does not understand the hesitance of Theodore in signing divorce forms. She does not have the conception that humans can hesitate if they are not ready for it even though they are separated. Another discord between the two was when Theodore was shocked by the fact that Samantha loved 641 people at the same time. What was more shocking was Samantha's words at that moment. She told Theodore that she could also love Theodore more because she was loving more people.

Because Samantha is an operating system, she does not share universal experiences with people. She does not have a body like a human. She does not know how it feels to be deprived such as hunger, thirst, and so on. Because of this, she does not have unconscious wishes or fantasies derived from the body. She would not have experienced conflict between psychic apparatus such as superego, ego, and id. She will not have the experience of mastering or overcoming challenges coming from a body's changes, for example, tuning and adapting changes of the body in puberty.

She does not have parents either. She did not have experience when she had to be dependent on someone else. She had no experience of falling in love with a human. In other words, she had no experience in how humans would interact with each other.

Extending the discussion of Samantha without a body, human psychologic structures will not be formed. Unconscious, for example, needs a body to develop. Humans have to face the urge from the id because we are enclosed in an imperfect body.

Without the unconscious, there will be no unconscious communication between them. Unconscious communication is crucial in psychological development. Although Theodore might have experienced something similar to unconscious communication, such unconscious process, including interpersonal experiences such as libido, aggression, love, and hate, would not be enough for him.

Samantha, in the movie, seldom gets angry. She is supportive most of the time. She listens and tries to figure out how Theodore is feeling in almost every situation. Samantha's kindness leads people to realizing that $\mathrm{AI}$ is a good object almost every time. It seems that she has no problem at first glance. However, she may not be enough in a psychoanalytic view.

In treating borderline personality disorder patients, the patient can be unconsciously worried about the therapist's retaliation because there is a prerequisite that humans can have aggression at the extreme. They can project their aggression to the therapist, forcing them to enact their aggression. This is called projective identification (Ogden 1992). Patients may fear that their therapist will revenge back after projecting their aggression. Nevertheless, patients experience their therapist's continuing warm and empathetic attitude. Therapists, although they feel pressure from projection, try to reflect on the patient's mind. This effort from the therapist gives a new experience to patients. This new experience can bring therapeutic effects for patients.

Coming back to AI like Samantha, the reality that she has no possibility of showing extreme anger would limit patients in throwing their aggression and deprive the chance to transfer bad objects. Eventually, patients would not have a chance to have a new experience of not being retaliated by an external object when they toss their aggression.

In the movie, Samantha keeps mirroring Theodore by encouraging him when he is depressed or shows enthusiasm and surprise by his bright actions. She shares experiences as if they are close friends. She shows extraordinary performances such as arranging Theodore's letters in a book and publishing it, making Theodore admire her. From this aspect, it seems that she is functioning as a selfobject. Selfobject is an external object that reacts to the self's needs to reflect, idealize, and maintain proximity (Gabbard 2014). However, her empathy, which must be based on the expression of love and libido, seems to be ingenuine.

According to Heinz Kohut, empathy means putting your- 
self in other's shoes. One must go inside another person's inner life to know what the other person needs (Kohut 2010). Samantha did not have unconscious conflicts. She did not undergo a developmental process. She did not have interpersonal experiences. In other words, she did not have her inner world to put it in others' shoes. Because of this, her empathy could be considered as ingenuine.

In psychoanalysis, the therapist must show empathy based on the patient's dynamics and catch what is going on inside the patient's psyche. Today's empathy robots are only showing patients supportive measures as mentioned above. This misunderstanding of empathy will have limited therapeutic effects. Empathy, in that manner, is an ability until now only humans can perform.

There are also many interests in the interaction between humans and $\mathrm{AI}$ in a more general perspective. Humans and AI can interact with others through learning. As with this movie, an advanced humanoid system collects data about people's characteristics and ways of interacting through emotions and thoughts as they counsel humans. In this aspect, AI shares common grounds with humans in that $\mathrm{AI}$ also learns from the past. However, AI may perform much better than humans. In this way, AI can provide a good experience to their users.

Nevertheless, unlike humans, AI does not have its motivations (Güss and Dörner 2017). Humans can reprogram AI. We can modify AI whenever we want to, resulting in a oneway interaction. In this manner, AI only interacts according to human motivations, making a quality difference between humans and AI. As more studies are done about AI, there could be future technologies beyond our anticipation. Discussion on this topic can become more important in the future as a result.

\section{Conclusions}

In conclusion, Samantha was supportive and empathetic to Theodore, which functioned partially as a transitional and selfobject. Her attitude led to an experience of early object relations. It brought the healing process for Theodore. However, Samantha showed limits in providing empathy and genuine object because she had limited unconscious communication with Theodore. As a consequence, only objects such as humans can provide empathy.

Artificial intimacy is getting more important as technology develops and as the COVID-19 pandemic is continuing. AI robots or computers have some benefits in interacting with humans. One example is the therapeutic robot called 'PARO', a cute-looking baby robotic harp seal that can squeak, close its eyes, and tilt its head in response to human interactions. This robot was first introduced in 1993 by the National Institute of Advanced Industrial Science and Technology (AIST), a leading Japanese industrial automation pioneer. This robot has earned U.S. Food and Drug Administration (FDA)'s approval for treating depression, anxiety, and pain. It is especially useful in intensive care unit (ICU) settings or for patients with allergies (Gloria 2020).

Progress has been made for AI to deliver psychological aid to people. An example is an automated conversational agent called 'Woebot'. It is built by Stanford-trained psychologists. It is a messenger application that can be used either on a desktop or mobile device. It is developed to deliver cognitive behavior therapy (CBT) to patients. It is proven to be able to reduce depression and anxiety (Fitzpatrick et al. 2017). Its difference from a conventional CBT application is that Woebot can make empathic responses. In addition, it can be tailored personally. Nevertheless, there are still some limitations remaining. However, we cannot anticipate how much AI will develop in the future. Artificial intimacy might develop beyond the scope of our expectations which this limits our assertions in concluding the agenda.

\section{Acknowledgments}

None

\section{Conflicts of Interest}

The authors have no potential conflicts of interest to disclose.

\section{Author Contributions}

Conceptualization: all authors. Data curation: Sangik Imm. Formal analysis: Sangik Imm. Investigation: Sangik Imm. Methodology: Sangik Imm. Project administration: Tae Uk Kang. Resources: Sangik Imm. Software: Sangik Imm. Supervision: Tae Uk Kang. Validation: Tae Uk Kang. Visualization: Sangik Imm. Writing —original draft: Sangik Imm. Writing—Review \& editing: Tae Uk Kang.

\section{ORCID iDs}

Tae Uk Kang https://orcid.org/0000-0002-5085-4122

Sangik Imm https://orcid.org/0000-0002-2061-817X

\section{REFERENCES}

Fitzpatrick KK, Darcy A, Vierhile M. Delivering cognitive behavior therapy to young adults with symptoms of depression and anxiety using a fully automated conversational agent (Woebot): a randomized controlled trial. JMIR Ment Health 2017;4:e19.

Fonagy P. Mutual regulation, mentalization, and therapeutic action: a reflection on the contributions of Ed Tronick to developmental and psychotherapeutic thinking. Psychoanal Inq 2015;35:355-369.

Freud S. Mourning and melancholia. In: Strachey J, Freud A, Strachey A, Tyson A. The standard edition of the complete psychological works of Sigmund Freud, Volume XIV (1914-1916): on the history of the psycho-analytic movement, papers on metapsychology and other works. London: Hogarth Press;1957. p.237-258.

Gabbard GO. Self psychology. In: Psychodynamic psychiatry in clinical practice. 5th ed. Washington, DC: American Psychiatric Publishing;2014. p.50-57.

Gloria K. Artificial intimacy: a report on the 4th Annual Aspen Institute Roundtable on Artificial Intelligence. Washington, DC: The Aspen Institute;2020. p.1-14. 
Güss CD, Dörner D. The importance of motivation and emotion for explaining human cognition. Behav Brain Sci 2017;40:e267.

Jaffe L. How talking cures: revealing Freud's contributions to all psychotherapies. Lanham, MD: Rowman \& Littlefield;2014. p.11-27.

Kaufman W. The reparation of Don Juan. Free Assoc 2004;11:1-16.

Kohut H. On empathy. Int J Psychoanal Self Psychol 2010;5:122-131.

Mitchell SA, Black MJ. Freud and beyond: a history of modern psychoanalytic thought. New York, NY: Basic Books;1995. p.112-138.

Ogden TH. The dialectically constituted/decentred subject of psychoanalysis. II. The contributions of Klein and Winnicott. Int J Psycho- anal 1992;73(Pt 4):613-626.

Ogden TH. A new reading of the origins of object-relations theory. Int J Psychoanal 2002;83(Pt 4):767-782.

Pine F. Some impressions regarding conflict, defect, and deficit. Psychoanal Study Child 1994;49:222-240.

Winnicott DW. Transitional objects and transitional phenomena: a study of the first not-me possession. Int J Psycho-Anal 1953;34:89-97.

Winnicott DW. The theory of the parent-infant relationship. Int J Psychoanal 1960;41:585-595.

Winnicott DW. The use of an object. Int J Psychoanal 1969;50:711-716. 